\section{Dacryocystorhinostomy in South West England}

\author{
Abstract \\ Purpose To assess the pre-operative \\ management, surgical technique employed, \\ success rate and patient satisfaction following \\ surgery in patients undergoing \\ dacryocystorhinostomy (DCR) in South West \\ England.
}

Method Two hundred and forty-two patients who underwent DCR were retrospectively studied. A telephone questionnaire was used to assess patient satisfaction in $\mathbf{1 0 0}$ patients. Results One hundred and thirteen (46\%) patients had nasolacrimal duct obstruction, half of whom had a history of dacryocystitis, $70(29 \%)$ had canalicular obstruction and 8 (3\%) had mixed blockage. The site of blockage was not known or recorded in $\mathbf{5 1}$ patients $(22 \%)$. Seventy-five $(31 \%)$ patients underwent DCR, 151 (62\%) DCR with insertion of silicon tubes, 9 (4\%) DCR and Lester Jones tube, and 7 (3\%) canaliculodacryocystorhinostomy (CDCR). Overall an $83.5 \%$ success rate was reported by the surgeons. The success rate for patients with a history of dacryocystitis was $\mathbf{9 8 \%}$, for nasolacrimal duct obstruction $\mathbf{9 6 \%}$ and for canalicular obstruction $82 \%$. When the site of blockage was not known or recorded the success rate was $60 \%$. Where the name of the surgeon was not recorded there was a $15 \%$ successful outcome. Eighty per cent of patients reported some improvement in their

B. Beigi

W. Westlake

B. Chang

C. Marsh

J. Jacob

Department of

Ophthalmology

West of England Eye Unit Royal Devon and Exeter

Hospital

Exeter, UK

\section{J. Chatfield}

Clinical Audit Department West of England Eye Unit Royal Devon and Exeter Hospital

Exeter, UK

\section{B. Beigi}

Bristol Eye Hospital Lower Maudlin Street Bristol BS1 2LX, UK

Tel: +44(0)1179230060 Fax: $+44(0) 1179284686$
BIJAN BEIGI, WILLIAM WESTLAKE, BERNARD CHANG, CATHERINE MARSH, JOHN JACOB, JUDITH CHATFIELD success rate in patients with primary-acquired obstruction of the drainage system who had undergone dacryocystorhinostomy (DCR). Preoperative investigations, grade of surgeon, surgical techniques employed and their relationship to the rate of functional success were studied. The relationship between functional success as assessed by the surgeon and patient satisfaction was also studied.

\section{Patients and methods}

Forty consultant ophthalmologists in South West England were asked to complete a questionnaire for each patient under their care who underwent DCR between January 1994 and December 1995. Two hundred and forty-two completed questionnaires were returned by 32 consultants. The 8 remaining consultants did not routinely carry out DCRs. The data received were abstracted to a spread sheet for analysis. The chi-squared test and Fisher's exact test were used to test for statistical significance as appropriate. Where the consultants' consent was obtained, 100 patients were randomly selected and included in a telephone questionnaire.

\section{Results}

Two hundred and forty-two DCRs were included in the study. A mean of 20 DCRs were performed in each unit (range 3-61). The sample comprised 151 (62\%) female and 91 $(38 \%)$ male patients. The mean age was 61 years (range 1-90 years). The patients had a mean of four visits to the ophthalmic unit after referral (range 1-50 visits). They remained on the waiting list from 1 month to 20 years (mean 6 months).

The main presenting complaint was epiphora in 184 patients (76\%), visual disturbances in $5(2 \%)$ and dacryocystitis in $53(22 \%)$.

The site of the blockage based on pre- and per-operative findings, and the corresponding surgical success rate as expressed by the surgeon at discharge or final follow-up, are given in Table 1. Mixed blockage refers to a blockage of one of the canaliculi and nasolacrimal duct, or common canaliculus and nasolacrimal duct. Patients with presumed 


\begin{tabular}{lccccccccc}
\hline & \multicolumn{1}{c}{ Site of blockage } \\
\cline { 2 - 10 } & Unicanicular Bicanalicular & $\begin{array}{c}\text { Common } \\
\text { canalicular }\end{array}$ & Nasolacrimal & Mixed & Unknown & $\begin{array}{c}\text { Not } \\
\text { recorded }\end{array}$ & Total \\
\hline No. (\%) of sample & $5(2)$ & $7(3)$ & $58(24)$ & $113(46)$ & $7(3)$ & $43(18)$ & $9(4)$ & 242 \\
No. (\%) successful & $3(60)$ & $4(57)$ & $52(90)$ & $108(96)$ & $4(57)$ & $30(72)$ & $1(11)$ & $202(83.5)$ \\
No. unsuccessful & 1 & 2 & 3 & 3 & 2 & 7 & 5 & $23(9.5)$ \\
No. of results not recorded & 1 & 1 & 3 & 2 & 1 & 6 & 3 & $17(7)$ \\
\hline
\end{tabular}

functional obstruction and pump failure are included in those patients with unknown site of obstruction.

The best results, $98 \%$ known successful outcome, were achieved in DCR for dacryocystitis. In general, cases involving canalicular obstruction attained a lower success rate $(82 \%)$ than those with nasolacrimal duct obstruction (96\%). The outcome was favourable in only $59 \%$ of cases where the site of blockage was unknown or not recorded $(p<0.0001)$.

In the majority of cases the diagnosis was based on syringing and probing of the drainage system (183 patients; $76 \%)$. Sixty-one patients (25\%) underwent dacryocystography, and $20(8 \%)$ scintillography. A Jones test was performed in 5 cases ( $2 \%$ ) and the diagnosis was based on clinical judgement alone in 74 patients (31\%). Some patients underwent more than one diagnostic procedure.

Post-operatively 162 patients $(67 \%)$ reported no epiphora, $52(21 \%)$ mild epiphora and $17(7 \%)$ persistent epiphora. The information was not recorded in the remaining 11 cases (4.5\%) (Fig. 1).

At final follow-up or discharge, the surgeon judged 23 cases $(9.5 \%)$ to have been a failure and 202 cases $(83.5 \%)$ to have been successful. The surgeon's impression was unspecified in 17 cases $(7 \%)$.

The grade of surgeon performing the operation and corresponding success rate, as assessed by the surgeon at discharge or final follow-up, are shown in Table 2. There was no significant difference between the overall success rates of consultants and other grades of surgeon ( $p>0.7)$. There was a favourable outcome in only $15 \%$ of cases where the surgeon's name was not recorded on the operating notes $(p<0.00001)$. Surgeons who performed fewer DCRs did not have a lower success rate; however, the maximum performed by any one surgeon was 10 operations (Fig. 2), so all surgeons performed relatively few DCRs.

Eleven patients $(5 \%)$ had undergone a previous DCR on the same side, while 11 others $(5 \%)$ had previously undergone surgery to the other side. Eight of the patients undergoing repeat DCR had a successful outcome as assessed by the surgeon at discharge or final follow-up.

The type of operation employed and corresponding success rate are shown in Table 3. CDCR and the use of Lester Jones tubes was associated with a less successful result $(73 \%)$ than DCR with or without bicanalicular intubation $(p<0.05)$.

In 149 cases $(61.6 \%)$ the osteotomy size was not known or not recorded, in 81 cases $(33.5 \%)$ it was between 10 and $20 \mathrm{~mm}$ and in 12 cases (5\%) less than 10 $\mathrm{mm}$. In those cases where the data were available, the osteotomy size had no discernible effect on the success rate. All 11 cases where the osteotomy size was less than $10 \mathrm{~mm}$ were successful and 71 of the 75 cases with an osteotomy of 10-20 mm were successful ( $p>0.4)$.

In 167 cases $(69 \%)$ the surgeon sutured both the anterior and posterior flaps and in $57(24 \%)$ the anterior flaps alone were sutured. The information was not recorded in 18 cases $(7 \%)$. Where the information was available, similar results were obtained in patients who had both the anterior and posterior flaps sutured $(89 \%$ successful outcome) compared with those patients in

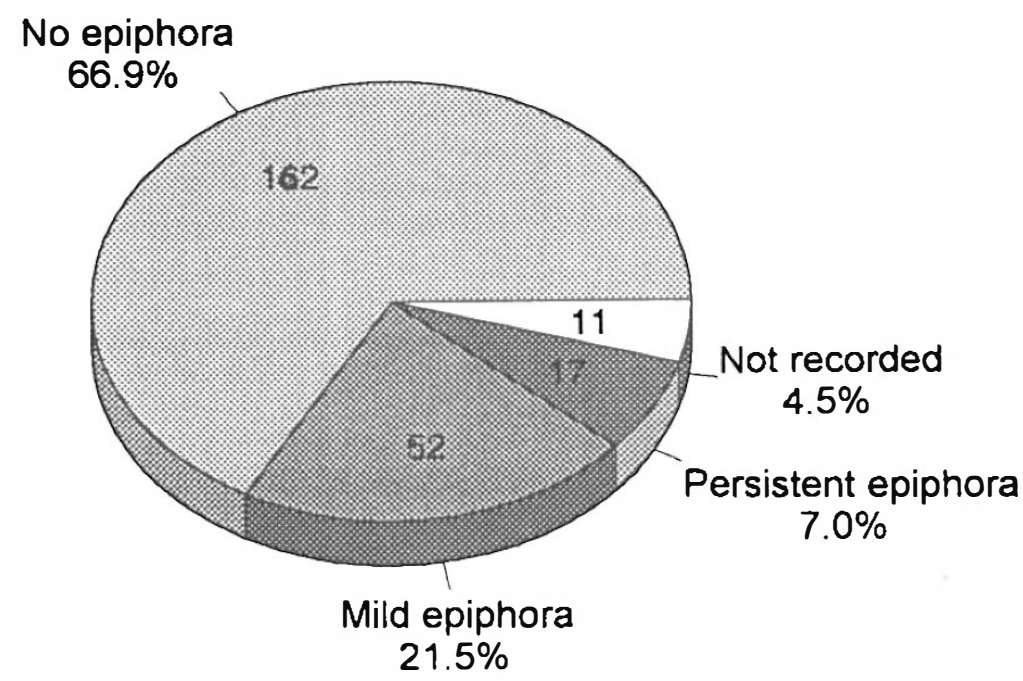

Fig. 1. Results of the operation. 


\begin{tabular}{|c|c|c|c|c|c|c|c|}
\hline & \multicolumn{7}{|c|}{ Grade of surgeon } \\
\hline & Consultant & Registrar & $\mathrm{SHO}$ & $\begin{array}{l}\text { Associate } \\
\text { specialist }\end{array}$ & $\begin{array}{l}\text { ENT surgeon } \\
\text { involved }\end{array}$ & $\begin{array}{c}\text { Not } \\
\text { known }\end{array}$ & Totals \\
\hline No. (\%) of sample & 147 & 43 & 4 & 25 & 3 & 20 & 242 \\
\hline No. (\%) successful & $132(90)$ & $39(91)$ & $3(75)$ & $23(92)$ & $2(67)$ & $3(15)$ & 202 \\
\hline No. unsuccessful & 8 & 3 & 1 & 1 & 1 & 9 & 23 \\
\hline No. of results not recorded & 7 & 1 & & 1 & & 8 & 17 \\
\hline
\end{tabular}

whom only the anterior flaps were sutured (91\% successful outcome), as judged by the surgeon at final follow-up.

In patients who had bicanalicular intubation there was a slightly higher success rate when the tubes were removed in the third and fourth post-operative months, but this difference was not significant (Fig. 3).

\section{Telephone data collection}

One hundred patients were contacted by telephone. Sixty-five per cent considered their surgery to have been a complete success. Fifteen per cent noticed some improvement and $20 \%$ considered their surgery unsuccessful. Twenty-five per cent of patients had complaints, such as discomfort with the tube, tube loss, and lack of information and advice on how to deal with the tube post-operatively. Nasal bleeding and mucus discharge had worried some patients, and others complained of ptosis. Twenty per cent of patients complained of difficulty with wearing spectacles due to paraesthesia of the incision site for up to 2 years after surgery. Seventy-five per cent of patients said that with hindsight they would undergo the same operation again, but $25 \%$ said they would not.

\section{Discussion}

Dacryocystorhinostomy was first reported by Toti in $1908 .^{2}$ He resected the medial wall of the lacrimal sac and the bone of the lacrimal fossa together with the anterior lacrimal crest, then made an opening in the nasal mucosa equal to the size of the opening in the lacrimal sac. Some nasal mucosa was left to overhang the periphery of the osteotomy. The reported success rate was $10-15 \%$. In 1921 Dupuy-Dutemps and Bourguet ${ }^{3}$ introduced the use of sutured anterior and posterior flaps and in 1933 Stein reported a favourable outcome in 55\% of 1000 cases using this technique.

Failure of DCR is caused by closure of the osteotomy site by soft tissue, canalicular disease and the 'sump mechanism' of epiphora, ${ }^{4}$ in which the lower part of the sac is not adequately drained and there is retention and overflow of tears despite a patent anastomosis. An osteotomy that is too small will be predisposed to closure, as will an inadequate anastomosis between the lacrimal sac and nasal mucosa. An inadequate anastomosis results from either a deficient incision or poor suturing of the lacrimal sac and nasal mucosa. Loose unsutured mucosa can grow over the osteotomy instead of covering the surface of the lacrimal drainage tract. A large clot in the ostium, adhesion to a deviated nasal septum, or obstruction by an inadequately excised anterior head of the medial turbinate can all contribute to the post-operative closure of the surgical ostium. The sac may be inadvertently anastomosed to an ethmoidal air cell. Untreated canalicular stenosis and lacrimal pump failure can also cause persistent epiphora.

The basic surgical principles and techniques of DCR remain similar to those of the early twentieth century.

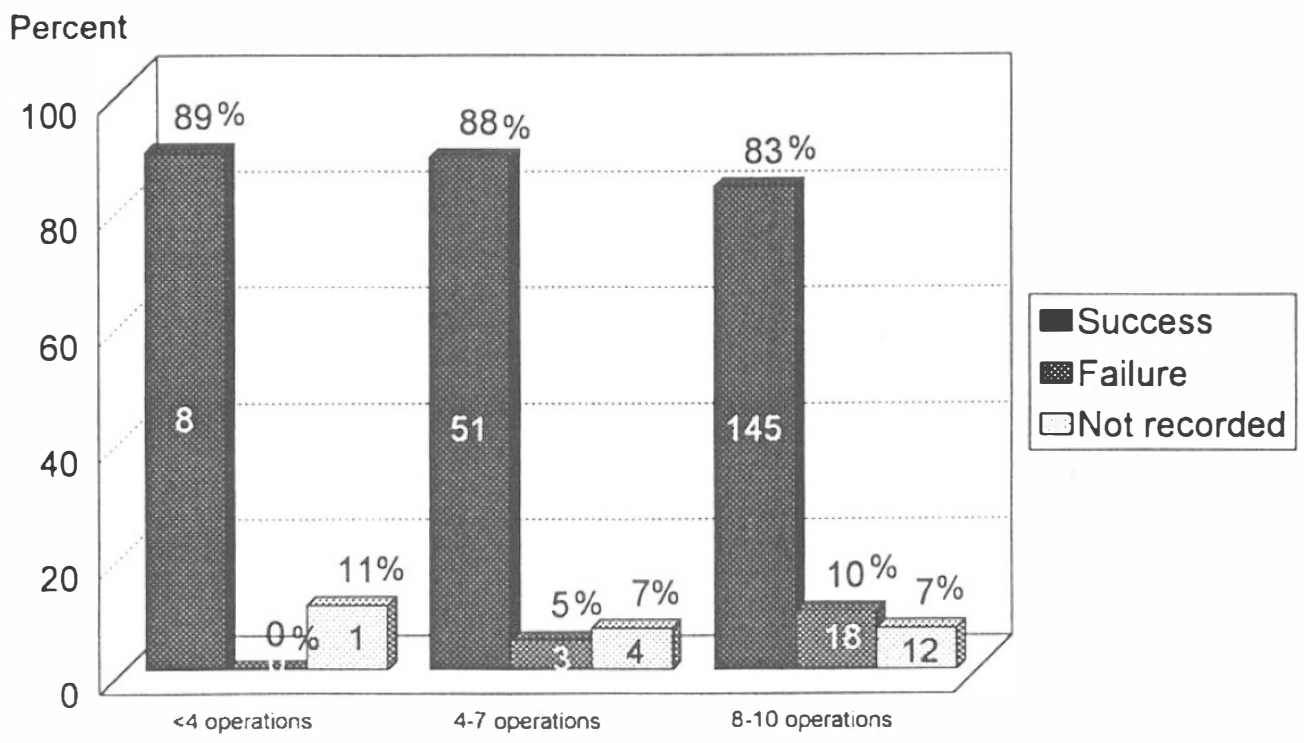

Fig. 2. Success/failure rate versus number of operations performed per surgeon. 


\begin{tabular}{|c|c|c|c|c|}
\hline & \multicolumn{4}{|c|}{ Type of surgery } \\
\hline & DCR & $\begin{array}{c}\text { DCR and } \\
\text { bicanalicular intubation }\end{array}$ & $\begin{array}{c}\text { DCR and } \\
\text { Lester Jones tube }\end{array}$ & CDCR \\
\hline No. (\%) of sample & $75(31)$ & $151(62)$ & $9 \quad(4)$ & 7 (3) \\
\hline No. (\%) successful & $62(83)$ & $129(85)$ & $6(67)$ & $5(71)$ \\
\hline No. unsuccessful & 7 & 12 & 3 & 1 \\
\hline No. of results not recorded & 6 & 10 & & 1 \\
\hline
\end{tabular}

Although other techniques incorporating the use of modern technology have been tried, the reported success rates remain similar to those using a conventional approach. Application of laser using either an external endocanalicular approach ${ }^{5}$ or endoscopic approach ${ }^{6,7}$ has a successful outcome reported in $70-90 \%$ of cases. Nasolacrimal dacryorecanalisation using tube dilatation or application of laser into the nasolacrimal duct has been described, with a successful outcome reported in $60-90 \%$ of cases. $^{8}$

A satisfactory result can be obtained in about $95 \%$ of patients following DCR for dacryocystitis. In patients with nasolacrimal duct obstruction the reported success rate is 70-99\%, whilst in patients with canalicular obstruction the outcome is less predictable, with $44-91 \%$ of patients achieving a satisfactory result. ${ }^{9-11}$ The success rate does depend on the criteria used to define success. We report a success rate of $65-90 \%$, the different figures depending on whether success is judged by the patient or surgeon. In our series the surgeons reported a failure rate of approximately $10 \%$, whereas in the telephone questionnaire $20 \%$ of patients considered their surgery to have been unsuccessful. On the other hand, $65 \%$ of patients were extremely satisfied and a further $15 \%$ described some improvement following surgery.

A larger osteotomy provides better access to the nasal mucosa, which in turn facilitates the fashioning and suturing of the flaps. In this series the osteotomy size was not recorded in the majority of cases $(56 \%)$, but it seems that the success rate was similar whether the osteotomy was described as being larger or smaller than $10 \mathrm{~mm}$ in diameter. However, it is unlikely that the osteotomy size was actually measured in the majority of cases, so some caution is needed in interpreting these results.

The use of bicanalicular silicon tubes is encouraged when there is a canalicular obstruction, a small lacrimal sac and a tight upper nasal cavity. The majority of cases in this series had insertion of silicon tubes. However, there are contradictory reports, some showing a higher success rate $^{9}$ and others a less favourable result ${ }^{10,12,13}$ when tubes are inserted. Walland and Rose ${ }^{14}$ found similar levels of success in the two groups, which agrees with our findings. Fifty-eight patients in our series had a common canalicular obstruction, yet only 7 underwent CDCR, the remainder being treated with DCR and bicanalicular intubation.

Displacement and loss of the tube can be avoided by suturing bicanalicular tubes in the upper nasal cavity near the osteotomy site. Silk sutures can produce pyogenic and giant cell granulomas at the site of the osteotomy and increase the failure rate. ${ }^{12,15}$ Nonabsorbable monofilament sutures and silicon sleeves should therefore be used to restrain the tube at its proximal and distal end. ${ }^{16}$

In common with other reports we have not shown any difference in outcome according to whether the anterior flap alone or anterior and posterior flaps are sutured. A

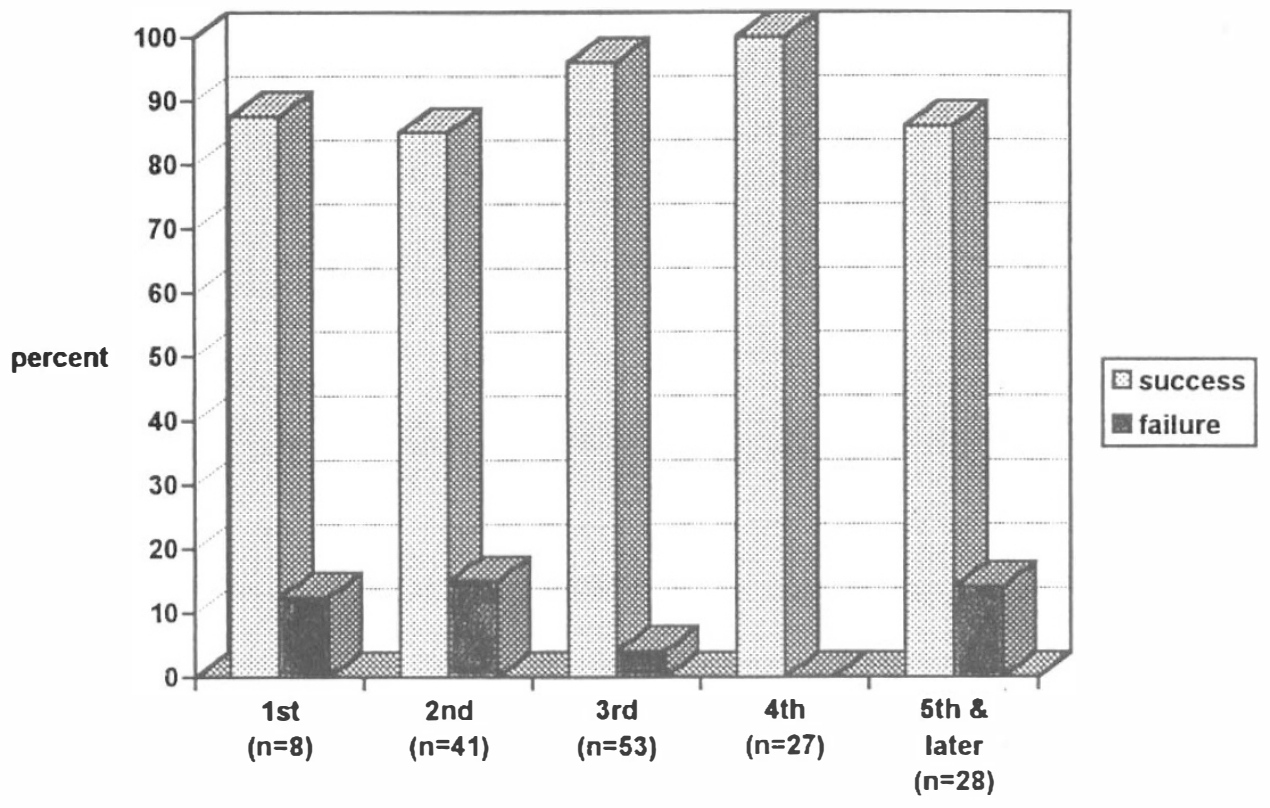

Fig. 3. Percentage outcome by month of tube removal. 
$90 \%$ success rate has been reported in DCR even without the use of flaps. ${ }^{17}$

Nine patients in this series had a Lester Jones tube placed. Seven of these had bicanalicular obstruction and one had common canalicular obstruction; in one patient with facial palsy the site of obstruction was unknown. All these patients had previously undergone lacrimal surgery. With appropriate patient selection good results are attainable following placement of a Lester Jones tube. Patient dissatisfaction with Lester Jones tubes varies from $9 \%$ to $32 \%$ in different reports. 18,19

A $15-35 \%$ level of patient dissatisfaction has been reported. This was usually related to a persistent epiphora caused by canalicular damage or blockage of the osteotomy site. ${ }^{20} \mathrm{Nasal}$ and periorbital haemorrhage can also cause concern among patients. This may result from poor haemostasis, blood dyscrasia or a ruptured anterior ethmoidal artery ${ }^{21,22}$ and is a potentially sightthreatening complication. Tube displacement, loss and irritation are other causes for dissatisfaction. An $8 \%$ rate of local post-operative infection has previously been reported ${ }^{23}$ and there are rare reports of cerebrospinal fluid leaks and meningitis. ${ }^{24}$ This did not occur in our series but the less severe complication of wound hyperaesthesia when wearing spectacles was reported by $20 \%$ of our patients.

\section{Conclusion}

The success rate of DCR performed in the South West Region is comparable to other reported results. Patients with dacryocystitis had the best outcome from surgery. There was a less favourable result when the canaliculi were involved. There was a high failure rate when the site of obstruction was not diagnosed pre-operatively, and also when records did not show clearly who the surgeon was. Proper pre-operative assessment, to identify the site of the blockage, is mandatory, and should preferably be carried out by the surgeon involved.

We would like to thank the Clinical Audit Department, Royal Devon and Exeter Hospital (Wonford) and all the consultant ophthalmologists in the South West Region for their help. We thank Mr A. Alaghebanian for his support.

\section{References}

1. Bartley GB. Acquired lacrimal drainage obstruction: an aetiologic classification system, case reports, and a review of the literature. Part 2. Ophthalmic Plastic Reconstr Surg 1992;4:243-9.

2. Toti A. Nuoro metodo conservatore di cura radicale delle suppurazioni croniche del saco Icarimale (dacriocistorinostomia). La Clinica Moderna 1904;10:385-7.
3. Dupuy-Dutemps L, Bourguet E. Precede plastique de dacryocystorhinostomy et ses resultats. Ann Ocul 1921;158:241-61.

4. Welham RAN, Henderson RPH. Results of dacryocystorhinostomy: analysis of causes for failure. Trans Ophthalmol Soc UK 1973;93:601-9.

5. Levin PS, Stormogipson DJ. Endocanalicular laser-assisted dacryocystorhinostomy: an anatomic study. Arch Ophthalmol 1992;110:1488-90.

6. Seppa H, Grenman R, Hartikainen J. Endonasal $\mathrm{Co}_{2}-\mathrm{Nd}$ :YAG laser dacryocystorhinostomy. Acta Ophthalmol (Copenh) 1994;72:703-6.

7. Boush GA, Lemke BN, Dortzbach RK. Results of endonasal laser-assisted dacryocystorhinostomy. Ophthalmology 1994;101:955-9.

8. Silkiss RZ. YAG nasolacrimal duct recanalization. Ophthalmic Surg 1993;24:772-4.

9. Rosen N, Sharir M, Moverman DC, Rosner M. Dacryocystorhinostomy with silicon tubes: evaluation of 253 cases. Ophthalmic Surg 1989;20:115-9.

10. Kunavisarut S, Phonglertnapagorn S. Dacryocystorhinostomy at Ramathibodi Hospital. J Med Assoc Thailand 1990;73:47-52.

11. Zapala J, Bartkowski AM, Bartkowski SB. Lacrimal drainage system obstruction: management and results obtained in 70 patients. J Craniomaxillofac Surg 1992;20:178-83.

12. Allen K, Berlin AJ. Dacryocystorhinostomy failure: association with nasolacrimal silicon intubation. Ophthalmol Surg 1989;20:486-9.

13. Psilas K, Eftaxias V, Kastaniondakis J, Kalogeropoulos C. Silicon intubation as an alternative to dacryocystorhinostomy for nasolacrimal drainage obstruction in adults. Eur J Ophthalmol 1993;3:71-6.

14. Walland MJ, Rose GE. The effect of silicon intubation on failure and infection rates after dacryocystorhinostomy. Ophthalmic Surg 1994;25:597-600.

15. Bartley GB. Acquired lacrimal drainage obstruction: an aetiologic classification system, case reports, and a review of the literature. Part 1. Ophthalmic Plastic Reconstr Surg 1992;8:237-42.

16. Glatt HJ, Putterman AM. Prevention of lateral migration of silicon tubes in dacryocystorhinostomy: selection of suture material [letter]. Ophthalmic Plastic Reconstr Surg 1993;9:302.

17. Becker BB. Dacryocystorhinostomy without flaps. Ophthalmic Surg 1988;19:419-27.

18. Rose G, Wellham R. Jones' lacrimal canalicular bypass tubes: twenty-five years experience. Eye 1991;5:13-9.

19. Rosen N, Ashkenazi I, Rosner M. Patient dissatisfaction after functionally successful conjunctivodacryocystorhinostomy with Jones tube. Am J Ophthalmol 1994;117:636-42.

20. Jordan DR, McDonald H. Failed dacryocystorhinostomy: the sump syndrome. Ophthalmic Surg 1993;24:692-3.

21. Bartley GB, Nichols WL. Haemorrhage associated with dacryocystorhinostomy and the adjunctive use of desmopressin in selected patients. Ophthalmology 1991;98:1864-6.

22. Vanhoucke K, Colla B, Missotten L. Dacryocystorhinostomy: indications, operations, results and some variants. Bull Soc Belge Ophtalmol 1990;238:103-10.

23. Walland WJ, Rose GE. Soft tissue infection after open lacrimal surgery. Ophthalmology 1994;101:608-11.

24. Beiran I, Pikkel J, Gilboa M, Miller B. Meningitis as a complication of dacryocystorhinostomy. Br J Ophthalmol 1994;78:417-8. 